\title{
Multipotent adult progenitor cells decrease cold ischemic injury in ex vivo perfused human lungs: an initial pilot and feasibility study
}

Saverio La Francesca ${ }^{1,6}$, Anthony E Ting ${ }^{2}$, Jason Sakamoto ${ }^{3}$, Jessica Rhudy ${ }^{3}$, Nicholas R Bonenfant ${ }^{4}$, Zachary D Borg ${ }^{4}$, Fernanda F Cruz ${ }^{5}$, Meagan Goodwin ${ }^{4}$, Nicholas A Lehman², Jennifer M Taggart ${ }^{2}$, Robert Deans ${ }^{2}$ and Daniel J Weiss ${ }^{4 *}$

\begin{abstract}
Background: Primary graft dysfunction (PGD) is a significant cause of early morbidity and mortality following lung transplantation. Improved organ preservation techniques will decrease ischemia-reperfusion injury (IRI) contributing to PGD. Adult bone marrow-derived adherent stem cells, including mesenchymal stromal (stem) cells (MSCs) and multipotent adult progenitor cells (MAPCs), have potent anti-inflammatory actions, and we thus postulated that intratracheal MAPC administration during donor lung processing would decrease IRI. The goal of the study was therefore to determine if intratracheal MAPC instillation would decrease lung injury and inflammation in an ex vivo human lung explant model of prolonged cold storage and subsequent reperfusion.

Methods: Four donor lungs not utilized for transplant underwent $8 \mathrm{~h}$ of cold storage $\left(4^{\circ} \mathrm{C}\right)$. Following rewarming for approximately $30 \mathrm{~min}$, non-HLA-matched allogeneic MAPCs $\left(1 \times 10^{7} \mathrm{MAPCS} / \mathrm{lung}\right)$ were bronchoscopically instilled into the left lower lobe (LLL) and vehicle comparably instilled into the right lower lobe (RLL). The lungs were then perfused and mechanically ventilated for $4 \mathrm{~h}$ and subsequently assessed for histologic injury and for inflammatory markers in bronchoalveolar lavage fluid (BALF) and lung tissue.
\end{abstract}

Results: All LLLs consistently demonstrated a significant decrease in histologic and BALF inflammation compared to vehicle-treated RLLS.

Conclusions: These initial pilot studies suggest that use of non-HLA-matched allogeneic MAPCs during donor lung processing can decrease markers of cold ischemia-induced lung injury.

Keywords: Lung transplantation, Ischemia-reperfusion injury, Cell therapy, Mesenchymal stromal cell

\section{Background}

Primary graft dysfunction (PGD) affects an estimated $10 \%$ to $25 \%$ of lung transplant recipients and is the leading cause of early posttransplantation morbidity and mortality [1]. PGD, defined by poor oxygenation in the immediate and early postoperative period, up to $72 \mathrm{~h}$ after transplantation, results from multiple pathologic mechanisms including donor lung ischemia, cold static organ preservation, and lung ischemia-reperfusion injury (IRI) [2]. The mechanisms of lung IRI have been extensively

\footnotetext{
*Correspondence: dweiss@uvm.edu

${ }^{4}$ Department of Medicine, University of Vermont College of Medicine, 226 Health Science Research Facility, Burlington, VT, USA

Full list of author information is available at the end of the article
}

investigated, and a common pathway is activation of inflammatory and immune mediators that are damaging to the lung allograft $[3,4]$. Thirty-day mortality rates are up to eightfold higher in lung transplant patients with severe PGD as compared with those without PGD. Associated signs and symptoms include interstitial/alveolar edema, increased pulmonary vascular resistance, intrapulmonary shunting, decreased lung compliance, and diffuse alveolar damage (DAD). Both PGD and DAD are associated with an earlier onset of bronchiolitis obliterans syndrome (BOS) and chronic rejection [5-12]. Despite recent advances in donor lung preservation [13], new therapeutic approaches to reduce IRI and thus both PGD and chronic rejection are desperately needed [14]. 
Adherent stromal (stem) cells isolated from bone marrow, adipose, and other sources, including mesenchymal stromal (stem) cells (MSCs) and multipotent adult progenitor cells (MAPCs), have potent immunomodulatory properties and have been increasingly investigated in a range of inflammatory and autoimmune conditions [15-17]. Notably, both systemic and intratracheal MSC administration reduces inflammation and injury in a wide spectrum of preclinical lung injury models [18,19]. Further, MSCs and MAPCs have limited immunogenicity, and thus, use of non-HLA-matched MAPCs and MSCs is increasingly found to be safe and potentially efficacious in a growing spectrum of clinical disease investigations including lung diseases [15-17]. Postulated mechanisms include release of anti-inflammatory cytokines and conversion of macrophages to anti-inflammatory M2 phenotype [15-17,20]. These properties make MSCs and MAPCs particularly interesting for use as a cellular therapy in solid-organ transplantation [21,22].

We hypothesized that administering MSCs or MAPCs to donor lungs would decrease potential lung inflammation resulting from storage and handling prior to implantation and thus decrease IRI with subsequent decrease in both PGD and in chronic rejection. To initially assess this in a preclinical translational pilot and feasibility study, we determined the impact of intratracheal administration of nonHLA-matched human bone marrow-derived allogeneic MAPCs, a cell type currently being investigated in clinical trials in other diseases [23-27] (MultiStem ${ }^{\oplus}$, Athersys Inc., Cleveland) in four human donor lungs not suitable for transplantation using an ex vivo human lung model of cold ischemia and subsequent reperfusion that reproduces current approaches to organ procurement and storage.

\section{Methods}

\section{Lung harvest and ex vivo perfusion}

Following informed consent, donor lungs not suitable for clinical use were procured under an established IRB protocol at The Houston Methodist (Houston Methodist Institutional Review Board protocol (2)1111-0205). The lungs were perfused with Perfadex (Vitrolife AB, Gothenburg, Sweden) and then stored in a refrigerator at $4^{\circ} \mathrm{C}$ for a total of 8 h. Ex vivo lung perfusion (EVLP) was then performed with a CE-marked Vivoline LS1 perfusion system (Vivoline Medical AB, Lund, Sweden) utilizing pH-adjusted Steen Solution (Vitrolife AB) containing meropenem $100 \mathrm{mg}$ (AstraZeneca AB, Sodertalje, Sweden) and 10,000 U of heparin (LEO Pharmaceutical, Copenhagen, Denmark) (Figure 1). The lungs were initially perfused at $0.5 \mathrm{~L} / \mathrm{min}$ and then warmed over $30 \mathrm{~min}$ to a target of $36^{\circ} \mathrm{C}$ with the flow rate increased gradually to a target of $70 \mathrm{~mL} / \mathrm{min}$ per kilogram of donor weight. When the perfusate temperature reached $32^{\circ} \mathrm{C}$, volume-controlled mechanical ventilation (Hamilton C2, Bonaduz, Switzerland) was started at an initial tidal volume of $3 \mathrm{~mL}$ per kilogram of donor weight with a positive end-expiratory pressure (PEEP) level of $5 \mathrm{~cm} \mathrm{H}_{2} \mathrm{O}$, a rate of $7-10$ breaths/min, and a $\mathrm{FiO}_{2}$ of 0.5 . Tidal volume was then increased gradually to a maximum of $7 \mathrm{~mL}$ per kilogram of donor weight.

\section{Cells and cell inoculations}

Human bone marrow-derived MAPCs were isolated from a single bone marrow aspirate, obtained with consent from a healthy donor, and processed and extensively characterized according to previously described methods [23-27]. In brief, MAPCs were cultured in fibronectincoated plastic tissue culture flasks under low oxygen tension in a humidified atmosphere of $5 \% \mathrm{CO}_{2}$. Cells were cultured to subconfluence in MAPC culture media (low-glucose DMEM [Life Technologies Invitrogen] supplemented with FBS [Atlas Biologicals, Fort Collins, CO], ITS liquid media supplement [Sigma], MCDB [Sigma], platelet-derived growth factor [R\&D Systems, Minneapolis, $\mathrm{MN}$ ], epidermal growth factor [R\&D Systems], dexamethasone [Sigma], penicillin/streptomycin [Life Technologies Invitrogen], 2-phospho-L-ascorbic acid [Sigma, St. Louis, $\mathrm{MO}$, and linoleic acid-albumin [Sigma]). Cells were passaged every 3-4 days, harvested using trypsin/EDTA (Life Technologies Invitrogen, Carlsbad, CA). The cells were positive for CD49c (90\%) and CD90 (90\%) and negative for MHC class II $(<1 \%)$ and CD45 $(<1 \%)$ (all Abs were from BD Biosciences, Franklin Lakes, NJ). Cells were subsequently cryopreserved at population doubling 30-35 in cryovials in the vapor phase of liquid nitrogen at a concentration of $1-10 \times 10^{6}$ in $1 \mathrm{~mL}$ (PlasmaLyte, 5\% HSA and $10 \%$ DMSO). Immediately prior to their use, MAPCs were

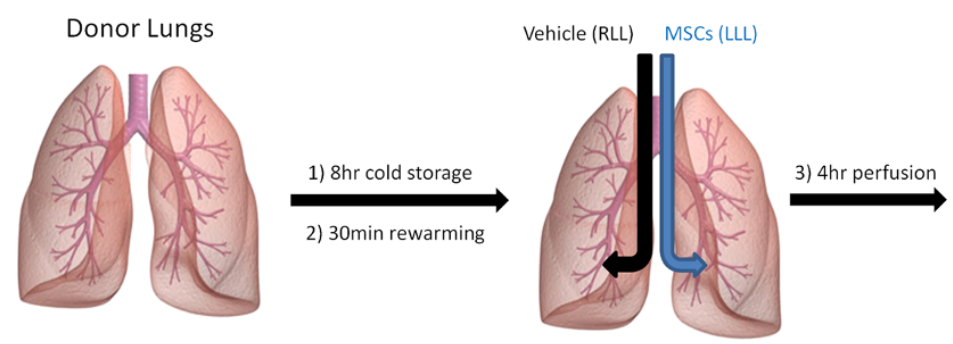

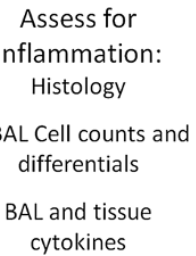

Assess for flammation:

AL Cell counts and

BAL and tissue cytokines

Figure 1 Schematic of study design. 
thawed and used directly. As per previous testing, there is no apparent loss of function of the MAPCs immediately following thawing in appropriate in vitro assays. All the studies performed to date with MAPC have used cells that have been cryopreserved and used directly after thawing. These include 16 publications as well as the utility in four clinical trials for AMI, GvHD, acute stroke, and ulcerative colitis [23-28].

Dose was determined based on prior studies with a sheep model for ARDS that also utilized intrabronchial delivery of MAPC [29]. Each study lung received a dose of $10^{7}$ MAPCs. Another lung inadvertently received a lower dose $\left(10^{6}\right.$ MAPCs) and so was not included in the overall assessments. Given the relatively small number of lungs in this pilot, we utilized an approach in which each lung was its own control, comparing cell administration in one lobe to vehicle administration in the contralateral lobe. When each lung temperature reached approximately $32^{\circ} \mathrm{C}$, cells were thawed, diluted into $19 \mathrm{~mL}$ of sterile saline, and administered by a bronchoscope into the proximal portion of the left lower lobe (LLL) bronchus. A similar volume of vehicle (20 mL of sterile saline) was similarly inoculated into the proximal portion of the right lower lobe (RLL) bronchus. Mechanical ventilation was initiated $5 \mathrm{~min}$ after cell or vehicle delivery.

\section{BAL fluid and tissue analyses}

Tissue biopsies were taken using a mechanical stapler (Covidien DST Series $^{\text {Ts }}$ GIA $^{\text {TM }}$ Staplers) prior to and 2 or $4 \mathrm{~h}$ after cell or vehicle infusions. Care was taken to obtain biopsies from the same areas, corresponding to the areas of cell or vehicle instillations. After $4 \mathrm{~h}$ of perfusion, the inoculated regions of the RLL and LLL were lavaged with $60 \mathrm{~mL}$ of saline and the BAL fluid assessed for total cell counts and cell differentials by three blinded observers, protein content, and levels of inflammatory cytokines determined by cytokine antibody array and ELISAs (R\&D Systems, Minneapolis, MN) [30,31]. The lungs were then fixed in $10 \%$ formalin for $1 \mathrm{~h}$ and a minimum of three to four biopsies taken from the areas of instillation. Mounted 5 - $\mu$ m paraffin sections of each biopsy piece were evaluated for inflammation on ten airways per animal in a blinded fashion by three individuals using an established semiquantitative scoring system as previously described [30,31]. Lung biopsy samples were homogenized and assessed for content of inflammatory cytokine mRNA by qPCR.

\section{Statistical analyses}

Groups were compared using either one-way or two-way ANOVA with a Fisher's LSD posttest or by direct analysis between two groups by Student's T-test, using a Welch's correction for unequal variances, as appropriate [30,31].

Full details for all methods are in Additional file 1.

\section{Results}

The relevant clinical characteristics of the donor lungs are summarized in Table 1. Donor age ranged from 44 to 66 , and two of the four donor lungs were obtained from patients with devastating neurologic events, one from asphyxia, and one from a motor vehicle accident. All of the lungs were not deemed suitable for transplant because of poor functional status including low $\mathrm{PaO}_{2}$ values with a mean of $184.8 \pm 49.3 \mathrm{mmHg}$ at $100 \% \mathrm{FiO}_{2}$ at a PEEP of $10 \mathrm{mmHg}$. These lungs also had radiographic abnormalities, variously including contusions, significant emphysema, or lobar collapse that did not respond to recruitment maneuvers in the operating room. All of the lungs also had radiographic signs of pulmonary edema with two having also pleural effusion, and all were noted to be variably edematous following surgical removal. Lung \#4 had RLL collapse on CXR but expanded following removal and bronchoscopic removal of mucus plugs.

A summary of the protocol utilized for each lung is presented in Table 2 and also in schematic form in Figure 1. Given the small number of lungs utilized for this pilot study, we chose to directly compare right to left lower lobes in each lung. Appreciating that any potential lung damage might be heterogenous, as could be best determined by gross appearance and radiographic assessments, the right vs left lower lobes were fairly similar for each of the lungs. Overall, the lungs had similar cold storage $(8 \mathrm{~h})$ and rewarming $(24.8+2.5 \mathrm{~min})$ times and subsequently similar reperfusion times $(3.6 \pm 0.8 \mathrm{~h})$ following bronchoscopic administration of cells or vehicle. At the end of the

Table 1 Clinical characteristics of the donor lungs

\begin{tabular}{|c|c|c|c|c|c|}
\hline Donor characteristics & 1 & 2 & 3 & 4 & Mean \pm SD \\
\hline Age & 55 & 56 & 44 & 50 & $51.25 \pm 5.5$ \\
\hline Sex & Male & Male & Male & Male & \\
\hline Cause of death & CVA & $\mathrm{SH}$ & Asphyxiation & MVA & \\
\hline $\mathrm{PaO}_{2}$ at $100 \% \mathrm{FiO}_{2}$ & 150 & 186 & 254 & 149 & $184.8 \pm 49.3$ \\
\hline PEEP & 10 & 10 & 10 & 10 & $10 \pm 0$ \\
\hline Radiographic findings & Infiltrate-edema & Infiltrate-edema & Infiltrate-edema & Edema-right lower lobe collapse, right pleural effusion & \\
\hline Lung appearance & Edematous & Edematous & Edematous & Contusions, edematous & \\
\hline
\end{tabular}

CVA cerebrovascular accident, $S H$ subarachnoid hemorrhage, MVA motor vehicle accident. 
Table 2 Summary of experimental protocol

\begin{tabular}{|c|c|c|c|c|c|}
\hline Donor lung & 1 & 2 & 3 & 4 & Mean \pm SD \\
\hline Duration of cold static storage (h) & 8 & 8 & 8 & 8 & $8.0 \pm 0$ \\
\hline Rewarming time (min) & 22 & 25 & 28 & 24 & $24.8 \pm 2.5$ \\
\hline Duration of ex vivo perfusion (h) & 4 & 2.5 & 4 & 4 & $3.6 \pm 0.8$ \\
\hline \multirow[t]{2}{*}{ Cells or vehicle delivered } & $10^{7} \mathrm{MSC}$ to $\mathrm{LLL}$ & $10^{7} \mathrm{MSC}$ to $\mathrm{LLL}$ & $10^{7} \mathrm{MSC}$ to $\mathrm{LLL}$ & $10^{7} \mathrm{MSC}$ to $\mathrm{LLL}$ & \\
\hline & Vehicle to RLL & Vehicle to RLL & Vehicle to RLL & Vehicle to RLL & \\
\hline
\end{tabular}

reperfusion period, there was some degree of further edema that had developed in each lung. However, overall, there was less visible edema and inflammation in the MAPC-treated (LLL) vs vehicle-treated (RLL) lobes. Representative images are shown in Figure 2.

Histologic assessment of the lungs at the end of the reperfusion period demonstrated that although patches of inflamed areas could be found in some of the MAPCtreated LLLs, there was significantly less overall inflammation in three out of the four lungs and also averaged over all four lungs, as assessed by semi-quantitative scoring of peribronchial, perivascular, and alveolar septal edema and by presence of inflammatory cell infiltrates (Figure 3). Representative photomicrographs are depicted in Figure 4.

Total BAL fluid cell counts were obtained in two out of four lungs (lungs 3 and 4). In both cases, there was a decrease of total BAL fluid cells in the MAPC-treated LLL compared to the vehicle-treated RLL (Figure 5A). Total BAL fluid cell counts were not obtained in the other lungs (lungs 1 and 2) due to inadvertent laboratory error. Cell differentials obtained on BAL fluid samples from all four lungs demonstrated a consistent increase in neutrophils and eosinophils in the vehicle-treated RLL that was ameliorated in the MAPC-treated LLL (Figure 5B).
Measurements of BAL fluid total protein levels was variable between the lungs, but a consistent decrease in total protein in the MAPC-treated LLL vs vehicle-treated RLL was observed in all four lungs (Figure 5C).

Levels of BAL fluid cytokines and chemokines demonstrated substantial variability between the different lungs. This included soluble anti-inflammatory mediators implicated in preclinical models of MAPC actions in lung injury and other models, such as IL-1RA, IL-10, STC, TGS-6, and iNOS. None of these were reliably or consistently increased in the MAPC-treated LLL in any of the four lungs (data not shown). Tissue mRNA levels were assessed in three of four lungs (lungs 2-4) by qPCR analyses of biopsy samples obtained prior to cell or vehicle administration and then after either 2 or $4 \mathrm{~h}$ of reperfusion period. Overall, patterns of tissue mRNA levels were more consistent between the three lungs. Comparable to BAL fluid levels of IL-10 protein, there was a strong early trend in elevated IL-10 in the LLL with a 3.5-fold increase in the levels of tissue IL-10 mRNA in the MAPC-treated LLL compared to only a 1.6-fold increase in vehicle-treated RLL as assessed at $2 \mathrm{~h}$ (Figure 6). Similar trends towards increases in LLL vs RLL were also observed at $2 \mathrm{~h}$ in mRNA levels of Angpt1 and STC1. Interestingly, for both

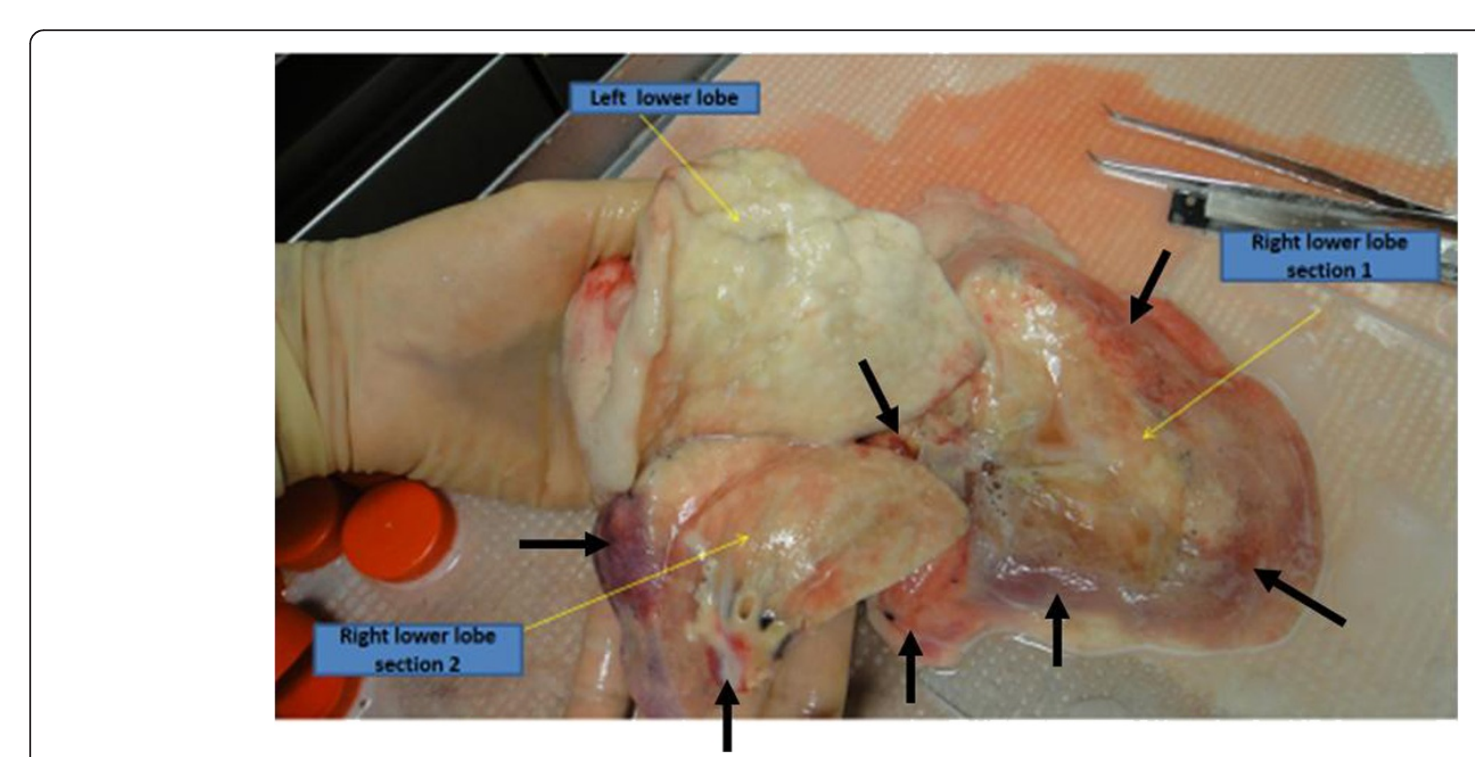

Figure 2 Representative gross appearances of the RLL and LLL of lung 2 following reperfusion. The MAPC-treated LLL appears normal while the vehicle-treated RLL appears edematous and inflamed. Black arrows indicate areas of edema and inflammation in the RLL. 

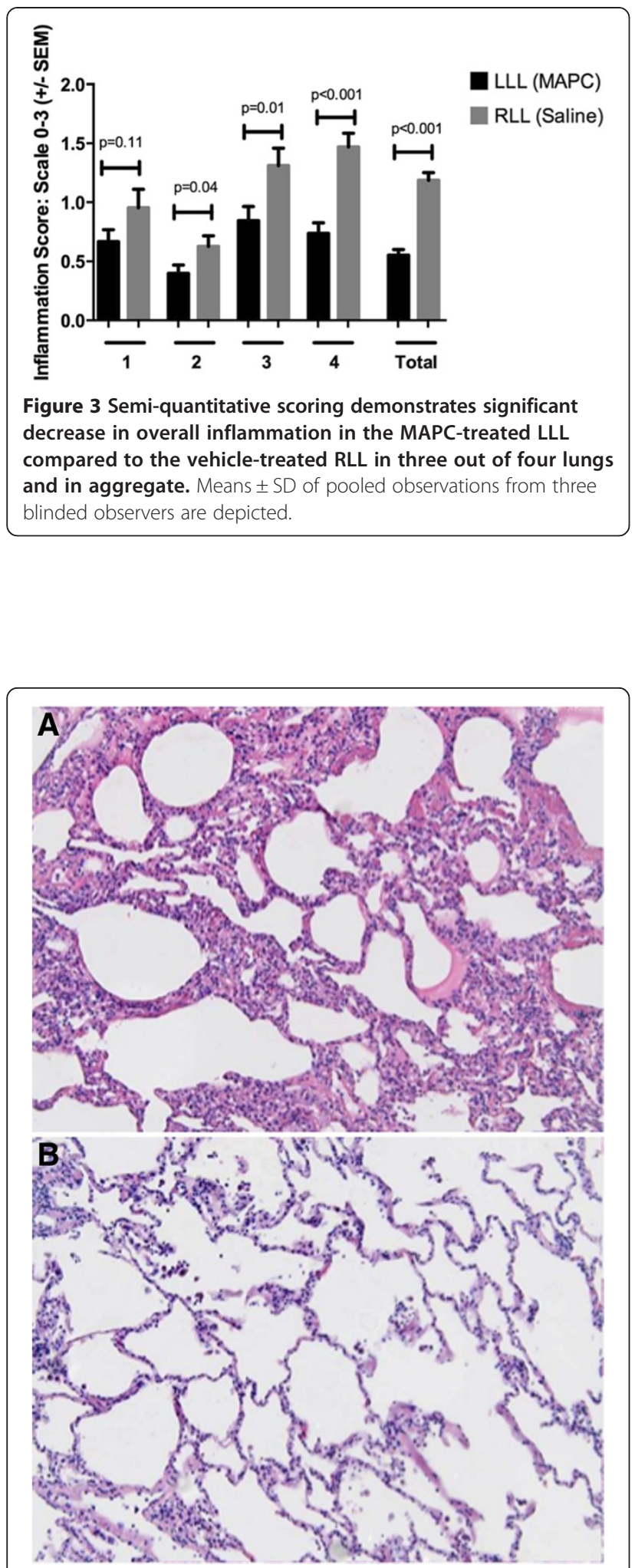

Figure 4 Representative photomicrographs from lung 1 demonstrate (A) alveolar septal thickening, edema, and perivascular and peri-bronchial inflammatory cell infiltrates in the control-treated RLL vs (B) minimal to no significant inflammation in MAPC-treated LLL. Original Mag $200 \times$. the LLL and RLL, there was a large increase in the fold expression of TSG6 from 2 to $4 \mathrm{~h}$. No clear patterns of changes were observed in mRNA levels of the other chemokines and cytokines evaluated including TGF $\beta$ and NOS2.

\section{Discussion}

In an initial small-scale pilot and feasibility study, we found that airway administration of bone marrow-derived MAPCs decreased a number of inflammatory markers provoked by prolonged cold storage and subsequent reperfusion in four suboptimal donor lungs. These results suggest that further studies to more fully investigate the potential anti-inflammatory effects of MAPCs and MSCs in models of IRI are warranted.

A number of different methods have been studied to improve the viability of donor lungs and to decrease either warm or cold ischemic inflammatory injury. These include a flushing solution with extracellular characteristics delivered both in an antegrade and in a retrograde fashion and the use of a portable ex vivo preservation system currently under clinical investigation for use during transport of donor lungs [14]. Different areas of research for therapeutic interventions aim to modulate the response induced by ischemia and reperfusion. For example, experimental animal models have shown a beneficial effect from gene therapy delivery of IL-10 [32] and from adenosine receptor activation [33,34]. However, while the experimental data are promising, it is unlikely that modulating one out of many inflammatory pathways can regulate a phenomenon that alters several cellular mechanisms involved, as innate and adaptive immunity, the activation of the complement cascade, endothelial dysfunction, and the triggering of cell death. In contrast, bone marrow-derived MSCs and MAPCs have the unique potential of acting on multiple inflammatory pathways involved in ischemia/reperfusion injury.

Systemic or intratracheal administration of bone marrowderived MSCs or MAPCs results in decreased inflammation and deleterious immune responses in a wide range of preclinical inflammatory disease models including experimentally induced acute lung injuries in mouse and in ex vivo perfused human lung models $[18,19]$. Furthermore, accumulating data in a growing number of clinical trials suggest that systemic administration of non-HLAmatched allogeneic MSCs and MAPCs is safe [23-27,35-37]. Thus, MSCs or MAPCs might conceivably be utilized to decrease IRI in donor human lungs with subsequent decrease in incidence of primary graft dysfunction and longer term complications of lung transplantation.

EVLP was originally designed as a method to assess the quality of lungs from donation after cardiac death (DCD) and from other nonacceptable donor lungs [38,39]. This technique is currently under clinical trial using asanguinous 

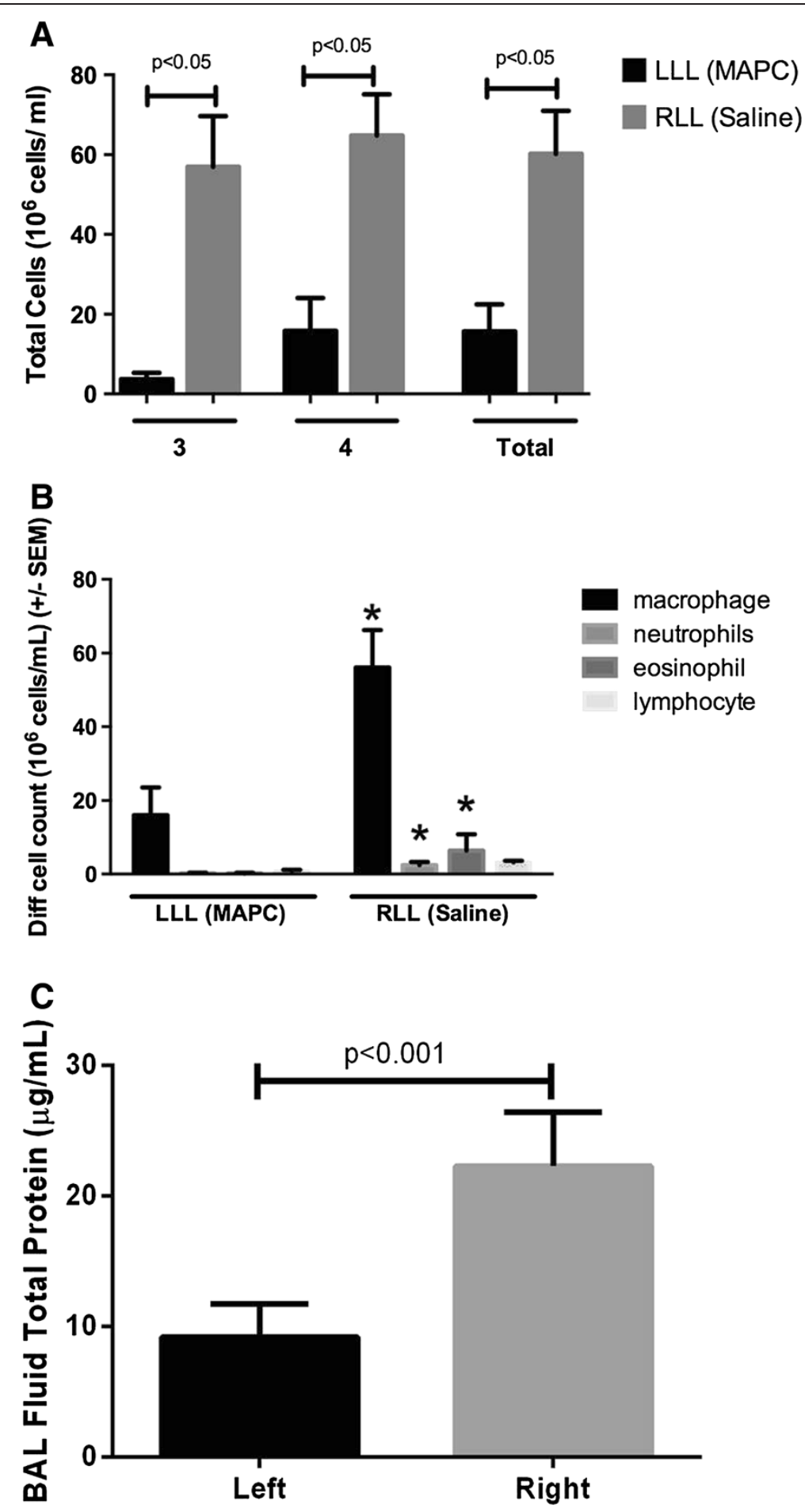

Figure 5 BAL fluid analyses. (A) Decrease in total BAL fluid cell counts in the MAPC-treated LLL in lungs 3 and 4. Total cell counts were not assessed in lungs 1 or 2 . Data represents total cell counts for each individual lung and means \pm SEM of the values obtained for each lung. (B) MAPC instillation also resulted in a significant decrease in the elevated numbers of BAL fluid total neutrophils and eosinophils in all four lungs. Data represents means \pm SEM of pooled observations from three blinded observers. *Significantly different from the corresponding LLL value. (C) BAL fluid total protein levels were lower at the end of the perfusion period in the MAPC-treated LLL vs vehicle-treated RLL. Data represents means \pm SEM. 

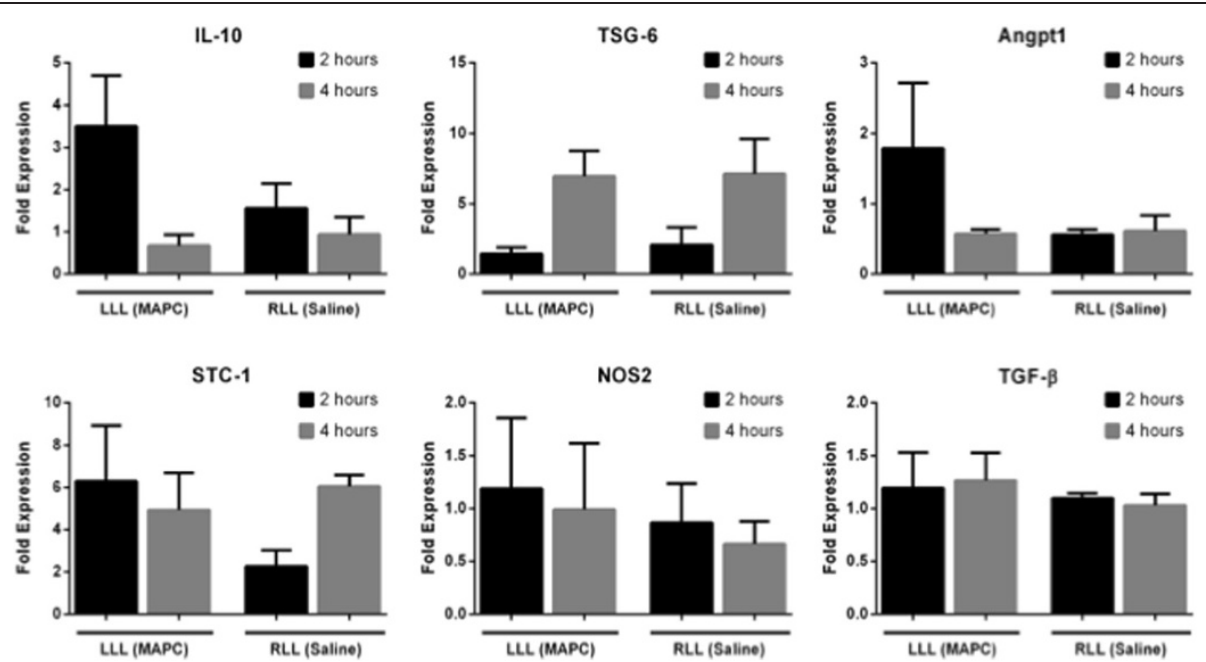

Figure 6 Cytokine analysis of lung tissue. GPCR analysis was performed on the lung tissue samples collected from the MAPC-treated LLL and vehicle-treated RLL of lungs 2-4 at $t=0,2$, and/or $4 \mathrm{~h}$. The fold expression represents the levels of the target gene compared to the $t=0$ value. All data were normalized to a housekeeping gene, GAPDH. Data represents means \pm standard deviations from LLL and RLL samples from lungs 2-4. Although strong trends towards differences at $2 \mathrm{~h}$ were observed in several of the measured mRNA levels of mediators typically associated with MSC immunomodulation, none reached statistical significance.

perfusates for the evaluation and reconditioning of potential donor lungs that under current criteria are not deemed suitable for transplant [40]. EVLP with asanguinous perfusates thus further offers an opportunity to administer MSCs or MAPCs directly into the donor lung by either intratracheal or intravascular routes prior to implantation. In an initial proof-of-concept pilot and feasibility study using an explant human lung model of cold ischemia and subsequent rewarming and reperfusion, a simple approach involving bronchoscopic instillation of bone marrow-derived MAPCs significantly decreased markers of inflammation and injury. Intriguingly, a similar reduction in inflammatory endpoints was also observed in the lower lobe of an additional lung in which tenfold fewer MAPCs were administered to the LLL (data not shown). These results suggest that MAPC or MSC administration to donor lungs may be a useful approach to both decrease PGD and also improve viability of suboptimal donor lungs. Indeed, a recent parallel study demonstrated that MSC administration reduced alveolar edema in failed donor human lungs [41]. We chose to initially assess direct airway MAPC administration into a single lobe with the contralateral lung as comparison to directly assess effects within each individual lung. This was done as the initial injuries to these areas appeared comparable and this was a straightforward approach to use for a pilot study. In particular, lower lobes tend to be most often affected by aspiration and other damage in ventilated brain-dead potential donors. Overall, the major advantage of this approach was the ability to obtain useful pilot data out of a smaller number of lungs. However, as the nature and degree of lung injury can be heterogenous, future larger scale studies will use complementary approaches such as MAPC vs vehicle administration in alternating whole lungs. With larger scale studies, the lungs can be grouped accordingly to a number of clinical factors including radiographic infiltrates, $\mathrm{P} / \mathrm{F}$ ratio, cause of death, and length of ICU stay for example.

The cold ischemic storage ( $8 \mathrm{~h}$ of total cold storage) is comparable to currently utilized clinical approaches. We also chose to use "off the shelf" non-HLA-matched MAPCs as proof of feasibility. Given the short time period in which transplantation needs to occur after identification of a donor lung and suitable recipient, it is not yet feasible to consider isolating and expanding MSCs or MAPCs from either the donor or recipient. Further, it is conceivable that MSCs or MAPCs obtained from patients with lung diseases may be adversely affected by the underlying pathophysiologic mechanisms. Nonetheless, given clinical variability between lungs and lobes within each lung and the relatively small sample size, the current pilot data is still compelling in its consistency of an ameliorating effect of MAPC administration in reducing BAL fluid total cell counts, protein, and histologic inflammation.

These findings need to be further explored, clarified, and validated in a larger number of lungs and under different paradigms of cold storage injury conditions, dose and timing of cell administration, and experimental approaches involving MAPC vs vehicle administration to alternating lungs as compared to lobar comparisons within each lung. Future studies will also investigate conditioned media and microsomal particles produced by the cells to see if these can convey similar effects. Physiologic endpoints including alveolar fluid clearance, as 
recently demonstrated to be improved by MSC administration in ex vivo perfused human lungs [40], and oxygenation will be included. Future studies will further assess MSC effects on endothelial injury in the perfused lungs. We did not assess localization, clearance or removal of the MAPCs from the donor lungs, or the effect of the lung environment on MAPC function, but these also need to be evaluated. Assessment in preclinical models of lung transplantation will also provide critical correlative information. If the pilot results are validated, this approach may be a simple and effective means of decreasing IRI.

\section{Additional file}

Additional file 1: Supplemental materials and methods.

\section{Competing interests}

Drs. Ting and Deans, Mr. Lehman, and Ms. Taggart are all employees of Athersys Inc., the sponsor of this study. Dr. Weiss has received an unrestricted research grant from Athersys Inc. There are no other competing interests.

\section{Authors' contributions}

RD, SLF, AET, and DJW have involvement in the conception, hypotheses delineation, and design of the study, acquisition of the data or the analysis and interpretation of such information, and writing the article or substantial involvement in its revision prior to submission. NAL, JR, JS, and JMT have involvement in the acquisition of the data or the analysis and interpretation of such information. NB, ZDB, FFC, and MG have involvement in the acquisition of the data or the analysis and interpretation of such information and writing the article or substantial involvement in its revision prior to submission. All authors read and approved the final manuscript.

\section{Acknowledgements}

The authors would like to thank Anna Söderlund for her support in using the Vivoline system. The authors also thank Ken Hartgett and Michael Bocci for the Respiratory Services. Studies were also supported by NIH ARRA RC4HL106625 (DJW), NHLBI R21HL094611 (DJW), and NHLBI R21HL108689 (DJW).

\section{Support}

Support for these studies was provided by Athersys Inc. to The Houston Methodist and Dr. La Francesca.

\section{Author details}

${ }^{1}$ Cardiac Surgery and Cardiopulmonary Transplantation, DeBakey Heart and Vascular Center, The Houston Methodist, Houston, TX, USA. ${ }^{2}$ Athersys Inc., Cleveland, OH, USA. ${ }^{3}$ Department of Nanomedicine, Houston Methodist Research Institute, Houston, TX, USA. ${ }^{4}$ Department of Medicine, University of Vermont College of Medicine, 226 Health Science Research Facility, Burlington, VT, USA. ${ }^{5}$ Federal University of Rio de Janeiro, Rio de Janeiro, Brazil. ${ }^{6}$ Current address: Harvard Apparatus Regenerative Technology, Inc., Holliston, MA, USA.

Received: 15 June 2014 Accepted: 29 September 2014

Published: 1 November 2014

\section{References}

1. Lee JC, Christie JD: Primary graft dysfunction. Proc Am Thorac Soc 2009, 6(1):39-46.

2. de Perrot M, Liu M, Waddell TK, Keshavjee S: Ischemia-reperfusion-induced lung injury. Am J Respir Crit Care Med 2003, 167(4):490-511.

3. den Hengst WA, Gielis JF, Lin JY, Van Schil PE, De Windt LJ, Moens AL: Lung ischemia-reperfusion injury: a molecular and clinical view on a complex pathophysiological process. Am J Physiol Heart Circ Physiol 2010, 299(5):H1283-H1299.

4. Weyker PD, Webb CAJ, Kiamanesh D, Flynn BC: Lung ischemia reperfusion injury: a bench-to-bedside review. Semin Cardiothorac Vasc Anesth 2013, 17:28.
5. Hall DJ, Baz M, Daniels MJ, Staples ED, Klodell CT, Moldawer LL, Beaver TM: Immediate postoperative inflammatory response predicts long-term outcome in lung-transplant recipients. Interact Cardiovasc Thorac Surg 2012, 15(4):603-607.

6. Huang HJ, Yusen RD, Meyers BF, Walter MJ, Mohanakumar T, Patterson GA, Trulock EP, Hachem RR: Late primary graft dysfunction after lung transplantation and bronchiolitis obliterans syndrome. Am J Transplant 2008, 8(11):2454-2462.

7. Bharat A, Kuo E, Steward N, Aloush A, Hachem R, Trulock EP, Patterson GA, Meyers BF, Mohanakumar T: Immunological link between primary graft dysfunction and chronic lung allograft rejection. Ann Thorac Surg 2008, 86(1):189-195.

8. Whitson BA, Prekker ME, Herrington CS, Whelan TP, Radosevich DM, Hertz MI, Dahlberg PS: Primary graft dysfunction and long-term pulmonary function after lung transplantation. J Heart Lung Transplant 2007, 26(10):1004-1011.

9. Carter YM, Gelman AE, Kreisel D: Pathogenesis, management, and consequences of primary graft dysfunction. Semin Thorac Cardiovasc Surg 2008, 20(2):165-172.

10. Warneckea G, Haverich A: Lung re-transplantation: review. Curr Opin Organ Transplant 2012, 17:485-489.

11. Snell Gl, Westall GP: The contribution of airway ischemia and vascular remodelling to the pathophysiology of bronchiolitis obliterans syndrome and chronic lung allograft dysfunction. Curr Opin Organ Transplant 2010, 15(5):558-562.

12. Diamond JM, Christie JD: The contribution of airway and lung tissue ischemia to primary graft dysfunction. Curr Opin Organ Transplant 2010, 15(5):552-557.

13. Pettersson $G B$, Budev $M$ : The role of ischemia in postlung transplantation complications. Curr Opin Organ Transplant 2010, 15(5):549-551.

14. Machuca TN, Cypel M, Keshavjee S: Advances in lung preservation. Surg Clin North Am 2013, 93(6):1373-1394.

15. Keating A: Mesenchymal stromal cells: new directions. Cell Stem Cell 2012, 10(6):709-716.

16. Prockop DJ, Oh JY: Medical therapies with adult stem/progenitor cells (MSCs): a backward journey from dramatic results in vivo to the cellular and molecular explanations. J Cell Biochem 2012, 113(5):1460-1469.

17. Bianco P, Cao X, Frenette PS, Mao JJ, Robey PG, Simmons PJ, Wang CY: The meaning, the sense, and the significance: translating the science of mesenchymal stem cells into medicine. Nat Med 2013, 19:35-42.

18. Weiss DJ: Stem cells, cell therapies and bioengineering in lung biology and diseases: comprehensive review of the literature. Ann Am Thorac Soc 2013, 10(5):S45-S97.

19. Matthay MA, Anversa P, Bhattacharya J, Burnett BK, Chapman HA, Hare JM, Hei DJ, Hoffman AM, Kourembanas S, McKenna DH, Ortiz LA, Ott HC, Tente W, Thebaud B, Trapnell BC, Weiss DJ, Yuan XJ, Blaisdell CJ: Cell therapy for lung diseases. Report from an NIH-NHLBI workshop, November 13-14, 2012. Am J of Resp and Crit/ Care Med 2013, 188(3):370-375.

20. Bedi SS, Hetz R, Thomas C, Smith P, Olsen AB, Williams S, Xue H, Aroom K, Uray K, Hamilton J, Mays RW, Cox CS Jr: Intravenous multipotent adult progenitor cell therapy attenuates activated microglial/macrophage response and improves spatial learning after traumatic brain injury. Stem Cells Transl Med 2013, 2:953-960.

21. Eggenhofer $E$, Popp FC, Mendicino M, Silber $P$, Van't Hof W, Renner $P$, Hoogduijn MJ, Pinxteren J, van Rooijen N, Geissler EK, Deans R, Schlitt HJ, Dahlke $\mathrm{MH}$ : Heart grafts tolerized through third-party multipotent adult progenitor cells can be retransplanted to secondary hosts with no immunosuppression. Stem Cell Trans Med 2013, 2(8):595-606.

22. Obermajer N, Popp FC, Johnson CL, Benseler V, Dahlke MH: Rationale and prospects of mesenchymal stem cell therapy for liver transplantation. Curr Opin Organ Trans 2014, 19(1):60-422.

23. Penn MS, Ellis S, Gandhi S, Greenbaum A, Hodes Z, Mendelsohn FO, Strasser D, Ting AE, Sherman W: Adventitial delivery of an allogeneic bone marrowderived adherent stem cell in acute myocardial infarction: phase I clinical study. Circ Res 2012, 110(2):304-311.

24. Maziarz RT, Devos T, Bachier C, Goldstein SC, Leis J, Cooke KR, Perry R, Deans RJ, Van't Hof WJ, Lazarus HM: Prophylaxis of acute GVHD using Multistem ${ }^{\oplus}$ stromal cell therapy: preliminary results after administration of single or multiple doses in a phase 1 trial. Biol Blood Marrow Transplant 2012, 18(2 Sup):S264-S265.

25. \#NCT01436487 (Study to examine the effects of MultiStem in ischemic stroke). [clinicaltrials.gov]. 
26. NCT01240915 (A study to investigate the safety and possible clinical benefit of Multistem $(r)$ in patients with moderate to severe ulcerative colitis). [clinicaltrials.gov].

27. \#NCT01841632 (Safety study of multipotent progenitor cells for immunomodulation therapy after liver transplantation). [clinicaltrials.gov].

28. Boozer S, Lehman N, Lakshmipathy U, Love B, Raber A, Maitra A, Deans R, Rao MS, Ting AE: Global characterization and genomic stability of human MAPC, a multipotent adult progenitor cell. J Stem Cells 2009, 4:17-28.

29. Rojas M, Cárdenes N, Kocyildirim E, Tedrow JR, Cáceres E, Deans R, Ting A, Bermúdez C: Human adult bone marrow-derived stem cells decrease severity of lipopolysaccharide-induced acute respiratory distress syndrome in sheep. Stem Cell Res Ther 2014, 5(2):42.

30. Lathrop MJ, Brooks EM, Bonenfant NR, Sokocevic D, Borg ZD, Goodwin M, Loi R, Cruz FF, Dunaway CW, Steele C, Weiss DJ: Mesenchymal stromal cells mediate Aspergillus hyphal extract-induced allergic airways inflammation by inhibition of the Th17 signaling pathway. Stem Cell Trans Med 2014.

31. Goodwin M, Sueblinvong V, Eisenhauer P, Ziats NP, Leclair L, Poynter ME, Steele C, Rincon M, Weiss DJ: Bone marrow derived mesenchymal stromal cells inhibit Th2-mediated allergic airways inflammation in mice. Stem Cells 2011, 29(7):1137-1148.

32. Cypel M, Liu M, Rubacha M, Yeung JC, Hirayama S, Anraku M, Sato M, Medin J, Davidson BL, de Perrot M, Waddell TK, Slutsky AS, Keshavjee S: Functional repair of human donor lungs by IL-10 gene therapy. Sci Trans/ Med 2009, 1(4):4-9.

33. Fernandez LG, Sharma AK, LaPar DJ, Kron IL, Laubach VE: Adenosine A1 receptor activation attenuates lung ischemia-reperfusion injury. J Thorac Cardiovasc Surg 2013, 145(6):1654-1659.

34. Mulloy DP, Sharma AK, Fernandez LG, Zhao Y, Lau CL, Kron IL, Laubach VE: Adenosine $\mathrm{A} 3$ receptor activation attenuates lung ischemia-reperfusion injury. Ann Thorac Surg 2013, 95(5):1762-1767.

35. Menasche P: Cardiac cell therapy: lessons from clinical trials. J Mol Cell Cardiol 2011, 50(2):258-265.

36. Hare JM, Fishman JE, Gerstenblith G, Difede Velazquez DL, Zambrano JP, Suncion W, Tracy M, Ghersin E, Johnston PV, Brinker JA, Breton E, Davis-Sproul J, Schulman IH, Byrnes J, Mendizabal AM, Lowery MH, Rouy D, Altman P, Wong Po Foo C, Ruiz P, Amador A, Da Silva J, McNiece IK, Heldman AW, George R, Lardo A: Comparison of allogeneic vs autologous bone marrow-derived mesenchymal stem cells delivered by transendocardial injection in patients with ischemic cardiomyopathy: the POSEIDON randomized trial. JAMA 2012 308(22):2369-2379.

37. Weiss DJ, Casaburi R, Flannery R, LeRoux-Williams M, Tashkin DP: A placebocontrolled, randomized trial of mesenchymal stem cells in COPD. Chest 2013, 143(6):1590-1598.

38. Wierup P, Haraldsson A, Nilsson F, Pierre L, Scherstén H, Silverborn M, Sjöberg T, Westfeldt U, Steen S: Ex vivo evaluation of nonacceptable donor lungs. Ann Thorac Surg 2006, 81(2):460-466.

39. Ingemansson R, Eyjolfsson A, Mared L, Pierre L, Algotsson L, Ekmehag B, Gustafsson R, Johnsson P, Koul B, Lindstedt S, Lührs C, Sjöberg T, Steen S: Clinical transplantation of initially rejected donor lungs after reconditioning ex vivo. Ann Thorac Surg 2009, 87(1):255-260.

40. Cypel M, Yeung JC, Liu M, Anraku M, Chen F, Karolak W, Sato M, Laratta J, Azad S, Madonik M, Chow CW, Chaparro C, Hutcheon M, Singer LG, Slutsky AS, Yasufuku K, de Perrot M, Pierre AF, Waddell TK, Keshavjee S: Normothermic ex vivo lung perfusion in clinical lung transplantation. N Engl J Med 2011, 364(15):1431-1440

41. McAuley DF, Curley GF, Hamid UI, Laffey JG, Abbott J, McKenna DH, Fang X, Matthay MA, Lee JW: Clinical grade allogeneic human mesenchymal stem cells restore alveolar fluid clearance in human lungs rejected for transplantation. Am J Physiol Lung Cell Mol Physiol 2014, 306(9):L809-L815.

doi:10.1186/2047-1440-3-19

Cite this article as: La Francesca et al:: Multipotent adult progenitor cells decrease cold ischemic injury in ex vivo perfused human lungs: an initial pilot and feasibility study. Transplantation Research 2014 3:19.

\section{Submit your next manuscript to BioMed Central and take full advantage of:}

- Convenient online submission

- Thorough peer review

- No space constraints or color figure charges

- Immediate publication on acceptance

- Inclusion in PubMed, CAS, Scopus and Google Scholar

- Research which is freely available for redistribution

Submit your manuscript at www.biomedcentral.com/submit
() Biomed Central 